DOI: https://doi.org/10.29105/gmjmx17.33-5

Artículos

\title{
TRAYECTOS DE LA PUBLICIDAD POPULAR: SEMIÓTICA DE LA GRÁFICA PUBLICITARIA EN ESPACIOS VISUALMENTE CONTAMINADOS EN EL CENTRO DE LIMA, PERÚ
}

\section{TRAJECTORIES OF POPULAR ADVERTISING: SEMIOTICS OF ADVERTISING GRAPHICS IN VISUALLY CONTAMINATED SPACES IN THE CENTER OF LIMA, PERU}

Eduardo Yalán Dongo

Universidad de Lima, Perú

ORCID: https://orcid.org/0000-0002-0143-4973

Autor para correspondencia: Eduardo Yalán Dongo, eyalan@ulima.edu.pe

\section{Resumen}

El objetivo del presente artículo es analizar el rol de los componentes plásticos de la publicidad popular en las interacciones comerciales en espacios de saturación y contaminación visual en el centro de Lima, Perú. Para ello, a través de técnicas cualitativas, se desarrolla un análisis semiótico sobre material gráfico recogido en el centro comercial Lima (Avenida Wilson, Cercado de Lima, Perú) con el propósito de identificar su papel en las interacciones de sentido comerciales que se asientan en los espacios de contaminación visual. Los resultados logran identificar una funcionalidad cooperativa de la publicidad popular con el trayecto de las interacciones comerciales a través de un uso gráfico excesivo de la dimensión plástica (cromática, eidética y topológica) y figurativa que, más que representar una realidad u ocultar significados abstractos, busca ser objetal, es decir, concretar la atracción, retención y anclaje de la caminata económica (acelerada y fugaz) hacia el consumo en el espacio público saturado.

Palabras clave: publicidad popular, semiótica visual, contaminación visual, etnosemiotica, diseño

\begin{abstract}
The main objective of this work is to analyze the role of the plastic components of popular advertising in commercial interactions in visual pollution spaces in the center of Lima, Peru. Therefore, through
\end{abstract}

Global Media Journal México 17(33). julio - diciembre 2020. Pp. 96-122. 
qualitative techniques, a semiotic analysis is developed on graphic material collected in the Lima shopping center (Avenida Wilson, Cercado de Lima, Peru) with the purpose of identifying its role in the commercial interactions that are based on visual contamination spaces. The results show a cooperative functionality of popular advertising with the course of commercial interactions through an excessive graphic use (chromatically, eidetic and topologically) of the plastic and figurative dimension that, rather than representing abstract realities or meanings, seeks to attract, retain, anchor the economic walk (accelerated and fleeting) in the public space.

Keywords: popular advertising, visual semiotics, visual pollution, ethnosemiotics, design

Recibido: 2020-10-22

Aceptado: 2020-12-23

\section{Introducción}

El discurso publicitario posee múltiples aristas de análisis e investigación, desde las representaciones visuales, los hechos narrativos y las precisiones semánticas que definen la estrategia comercial. El enfoque ha permanecido en su generalidad direccionado al desarrollo de los componentes del discurso circulante en plataformas mediáticas digitales $y$ novedosos formatos emergentes que cuantifican el impacto del discurso dentro del escenario global (Lee y Song, 2019). No obstante, pese a los 30 años de desarrollo heterogéneo en el campo de la investigación publicitaria, la motivación hacia el estudio de formatos populares de comunicación publicitaria es aún menor (Kim et al., 2014). Son las investigaciones ocupadas en el fenómeno de lo glocal las que han acercado el interés sobre el fenómeno conflictivo entre las tendencias internacionales y una semiótica regional. En este vector de investigación se entrecruzan formas de identidades locales o regionales con potentes regímenes de signos transnacionales en un entorno global que los fusiona y mercantiliza (Dürrschmidt y Kautt, 2018), a veces de forma orgánica y otras veces bajo una tensión conflictiva (Moraru, 2012). Es este espectro semiótico el que permite una pregunta más atenta hacia los formatos de una publicidad local que transparenta las dinámicas culturales y comerciales por demás saturadas y congestionadas por un mercado comercial itinerante e informal.

Es la publicidad local o popular la que ha formado parte de relaciones congestionadas de espacialidad, subjetividades aceleradas y estéticas regionales barrocas que han sido menospreciadas por una cultura publicitaria más entretenida en la descripción del impacto

Global Media Journal México 17(33). julio - diciembre 2020. Pp. 96-122. 
de campañas comerciales de alto presupuesto que en la producción de sentido y significación de la denominada publicidad popular o latinoamericana. Debido a este interés hacia formatos publicitarios ligados a economías formales y plataformas digitales de gran rentabilidad, las investigaciones sobre publicidad popular en el espacio público guardan relevancia a la vez que discontinuidad (Vakratsas y Ambler, 1999; FigueroaSaavedra, 2007; Fernández y Herrera, 2009; Dagatti y Siganevich 2013; Moreno, 2014; Hodges et al., 2016; Sánchez, 2017). Dichas investigaciones atienden el carácter histórico (como la memoria pública, ghost signs o el también denominado fading advertising), representativo y cultural del diseño popular más que su funcionamiento dentro de una economía informal.

Motivada por este contexto y vacío de investigación, la presente investigación pretende abordar el fenómeno publicitario desde la óptica de su singularidad semiótica como comunicación ligada íntimamente al espacio comercializado. El objetivo general se detiene en el análisis del rol de los componentes plásticos de la publicidad popular en las interacciones comerciales en espacios de saturación y contaminación visual en el centro de Lima, Perú. Comprendemos la intimidad existente entre la publicidad popular estéticamente comprendida y las interacciones sostenidas en una espacialidad creada como un hecho que define propiamente el paisaje latinoamericano. Se sostendrá que la estética de la publicidad popular transparenta, en una semiótica barroca y visualmente caótica, las dinámicas de un mercado local informal propio de pequeños propietarios y mayoristas poseedores de capital comercial (con relaciones complejas con un capital industrial o bancario) que explotan trabajo -formal e informal- asalariado (Rojas, 2014; Gago, 2014).

\section{Marco teórico}

\section{El espacio social como forma semiótica}

Desde una perspectiva semiótica, la pertinencia del espacio se presenta desde una lógica de la construcción. Esto quiere decir que el reconocimiento de un campo, espacio o territorio, implica la formación y creación indefectible de una forma de sentido que no es la fisonomía física común y dada de la ciudad (calles, techos, balcones, estructuras). Este criterio constructivista es la distinción principal entre el interés de la ciudad desde un punto de vista urbanístico, natural o arquitectónico y uno semiótico (Greimas y Courtés, 1982). Esta distinción es acentuada por Greimas (1980), quién presenta la diferencia entre la construcción espacial semiótica y el territorio físico en la síntesis categorial 'espacio' y 'extensión', 
respectivamente. El espacio semiótico es una forma orientada a los estados de cosas o las densidades del campo de sentido (el espacio familiar, festivo o ritual, no es una espacialidad física, sino sobreescritura semiótica en tanto puebla de sentido la vivienda arquitectónica), un ejercicio semiótico denominado por Greimas como 'forma'. Pese a la distinción común del signo en el espacio como una representación que oculta aquello que se representa (una ontología del territorio, de la ciudad), la semiótica como disciplina ocupada en el estudio de la significancia (Landowski, 2012), atiende a los signos como parte de un proceso de fluidificación del sentido y la significación, esto quiere decir que atiende menos a las identificaciones del espacio (rasgos inmutables e invariantes) para concentrarse más en el devenir de la espacialidad en tanto forma que se nos presentifica produciendo distintas capas de significancia y variación. De esta manera, la forma se revela como un proceso de coagulación animado por un fondo en constante construcción (deformación). Por consiguiente, la espacialidad presenta a las relaciones sociales, desde el punto de vista semiótico, como dramatizaciones o narrativizaciones que no se apropian de un espacio (en tanto este no es dado), sino que lo construyen y/o sobreescriben permitiendo la creación de un espacio semiótico o territorio simbólico (Fontanille, 2017).
Investigaciones lingüísticas sobre el espacio se han aproximado a esta forma topológica (espacialidad semiótica) como un ejercicio exclusivo del lenguaje, no obstante, desde la perspectiva de una praxis semiótica se atiende a la producción de sentido más allá de la formación lingüística o las formas orales que determinarían la construcción del espacio de sentido. Precisamente, las investigaciones semióticas contemporáneas determinan a la intensidad como una valencia extralingüística que se encuentra regulando este espacio semiótico o extensidad (Zilberberg, 2006, 2015). En una relación de dependencia con la intensidad, entendida como energía de sentido o fuerza fenoménica, el espacio semiótico deja de presentificarse como forma para entenderse como deformación (Zilberberg, 2000) en tanto encuentra variación y discontinuidad por la intensidad que le permiten adquirir esta composición dinámica y transformativa. Así, el territorio es intensivo en tanto permite vivificar o fluidificar una fuerza acogida.

Tal como afirma el semiotista italiano Pierluigi Basso-Fossali (2009), la institucionalización del espacio es fundamental en la producción de la subjetividad porque se la define como un 'lugar' [lieux]. Los lugares son zonas coaguladas, espacios de visibilidad que buscan organizarse como productores de valores constantes, valores de un sistema social particular e instituido. No obstante, nos recuerda Basso-Fossali, que el único lugar que 
guarda una indeterminación o forma de resistencia por devenir enteramente un espacio, el único espacio que realmente no está dispuesto a convertirse en un lugar fijo es la indeterminación del sujeto. Es el sujeto y no la subjetividad el que se presenta como un sitio [site], un "fuera de lugar" [fuori luogo] una perspectiva que se desliza en la curvatura del espacio, en su deformidad. Es lo que BassoFossali denomina espacio figural [l'espace figural], un sitio móvil, inestable, intraducible. No como característica o propiedad del sujeto, sino como efecto de una praxis de perspectivismo, de variación.

\section{Factores condicionantes del paisaje urbano}

El paisaje urbano se confirma dependiente de las transformaciones sociales y económicas que lo atraviesan. El indefectible crecimiento de la ciudad producto de los procesos de migración rural ha revelado fenómenos paralelos que han incrementado la polución en la circulación social y en la creación de un mercado laboral informal (Suryanto et al., 2020). Desde la década de los años cincuenta el fenómeno de la migración en el Perú se ha desarrollado de forma progresiva, acelerada y focalizada a la ciudad capital, Lima. Habitualmente se señalan como principales detonadores y condiciones de la migración peruana no solo la intensa inversión económica que desde el gobierno de Leguía se justificada por el proyecto de modernizar Lima para atraer capital extranjero, sino el conflicto armado interno que se agudizo en la década de los ochenta, la presencia de grupos políticos auto denominados contra hegemónicos $\mathrm{y}$ revelados posteriormente como partidos dogmáticos terroristas en los andes peruanos motivó a muchos a migrar a la ciudad (Martuccelli, 2015).

El acelerado proceso de desrruralización es uno de los factores más importantes que han motivado aún más la expansión capitalista en el Perú. Al centralizar la cobertura económica en la capital, los habitantes del campo indefectiblemente participaban en la consolidación expansiva del capitalismo preocupado por cosechar grandes porciones de mano de obra barata lista para ingresar en la manufactura precaria de la producción. Esta inserción de un trabajador asalariado manufacturero genero también, nuevamente producto de la intensa migración que se desarrollaba más en la década de los noventa, un ejército industrial de reserva laboral que orbitaba en torno al trabajo formal precario. Así, junto con la migración, se presenta otro fenómeno importante para la construcción de la ciudad y su visualidad, la informalidad (Bailón y Nicoli, 2009). Existe una evidencia de intimidad entre la mercantilización y el espacio público. Las grandes inversiones, generalmente financiadas bajo la lógica de la deuda, determinan la rápida urbanización de los centros de producción y circulación centralizados manteniendo una 
baja calidad de los costos de vida, al mismo tiempo que difuminan los usos políticos del espacio público cada vez más programado en el consumo (Harvey, 2014; Martuccelli, 2015).

El hecho informal en el Perú es largamente estudiado, sus aristas se encuentran enraizadas en los diversos motivantes migratorios cubiertos por las evidencias de una expansión económica liberal en el Perú y un sector informal que aporta 18.8 por ciento al PBI, mientras que representa el 55.9 por ciento del empleo total (INEI, 2019). Pese a su confirmada complejidad, es el interés aquí ocuparse únicamente de una de las expresiones del espacio de consumo informal, aquella que concentra las diversas dinámicas sociohistóricas en un texto de especial singularidad para la ciudad: la contaminación del paisaje público. Esta se desarrolla como fenómeno unificador de las experiencias migratorias antes señaladas, motivado también por la situación del trabajador precario que asiste a largas jornadas laborales en los centros de producción en el centro de la ciudad. Precisamente, es el centro de Lima el espacio productivo que convoca la aglutinación: desde oficinas institucionales del Estado, pequeños centros educativos hasta grandes zonas comerciales que rebasan los límites del espacio (Rojas, 2014). De aquí la emergencia de fenómenos que intervienen el paisaje como el tráfico intenso de automóviles, la visualidad congestionada de la plaza pública o el centro de compras. En suma, el paisaje visual contaminado es expresión de las congestiones urbanas y de una frágil composición de la economía de mercado (Flad, 1997).

\section{Saturación y contaminación visual del espacio}

La sociedad de consumo contemporánea contempla un innegable exceso de imágenes o saturación icónica que normaliza la contaminación visual. Para Selva y Solà (2004), la invisibilización de la saturación visual en el espacio público produce insensibilización en transeúntes y sujetos circulantes del espacio. Esto quiere decir, en palabras de Baudrillard (1969), que la saturación publicitaria produce una neutralización recíproca entre las imágenes comerciales por sus propios excesos. Dicho en otro modo, una sobreinformación naturalizada que se traduce en una desinformación colectiva, la banalización de la información como contenido de las imágenes. Los lazos de una banalidad icónica y la contaminación visual son íntimos (Kucharikova y Simko, 2017).

Se suele clasificar los naturalizados contaminantes visuales en distintos tipos: (i) el uso de vallas publicitarias y señalización, (ii) cables telefónicos y de comunicación, (iii) torres de redes y comunicaciones y (iv) basura en las calles (Ahmed et al., 2019). Tengamos 
en cuenta, al respecto, que estas deformaciones producidas por la migración y la aceleración económica de la ciudad industrializada, determinan el espacio semiótico. Como factores más importantes de la presentación congestionada visualmente del paisaje urbano pueden identificarse los medios de transporte urbanos, el circuito rebasado de movilidad, así como la concentración en el centro de la ciudad por la cercanía de los trabajadores al centro de producción (Portella, 2014). Ambos factores, convergentes a una creciente inversión publicitaria, provocan una sobreescritura en el espacio visual (el espacio extensivo o semiótico) que configura lo público comercial en conquista inmediata de lo privado. Desde un punto de vista semiótico, todo devine espacio público congestionado.

El fenómeno de esta congestión visual no ha pasado desapercibido por las diversas investigaciones nacionales e internacionales. La reiteración y aglutinación de elementos visuales motiva al trabajo de las ciencias sociales quienes han investigado este fenómeno bajo el concepto de contaminación visual [visual pollution]. La metodología de acercamiento a este problema implica desde el establecimiento del carácter general del paisaje al estudio de la capacidad visual del espacio contaminado, es decir, la evaluación de la visibilidad de un objeto contaminante según sus características físicas y visuales (Kamičaitytė-Virbašienė et al., 2015). La intervención es importante para la descongestión de espacio público, algunas investigaciones apuntan a la creación de diseños y tecnologías menos imponentes visualmente que podrían implementarse en ciertos casos (Furze, 2002). Entre ellas la actividad creativa que convoca vallas, graffitis y otras soluciones de diseño que podrían optimizar una crianza emocional en los ciudadanos (Bankole, 2013) o environmental beautification, además del ordenamiento territorial. El sistema de planificación estética de la ciudad se convierte en el proyecto de regulación propuesto en diferentes países en tanto que letreros y vallas publicitarias crean problemas de contaminación ambiental y afectan la planificación de la urbanización en las ciudades (Cercleux et al., 2016).

Los estudios empíricos sobre la contaminación visual asumen las perspectivas psicológicas partiendo de la teoría de la Gestalt sobre las relaciones entre el orden y el caos. De acuerdo con Adriana Portella (2014), son las representaciones ordenadas y la sintaxis visual simétrica las que influyen en la percepción de los consumidores de una ciudad comercial o en centros de consumo pequeños. Desde esta purga visual, la familia se convierte en un personaje económicos atractivos para la inversión en tanto su motivación de consumo se enraíza en la descontaminación del espacio. Esto quiere decir que la contaminación producida por las alteraciones visuales del paisaje urbano mantiene íntima relación no solo con la vitalidad urbana - por lo que 
mejorarla estéticamente implicaría un aumento en esta última (Nami et al., 2016; Szczepańska et al., 2019)—, sino en la vitalidad de consumo. Desde este punto de vista, en el caso peruano, el fenómeno de la publicidad exterior como la intervención publicitaria popular invasiva es especialmente preocupante en las áreas protegidas como patrimonio (centro de la ciudad) por la limitación y depreciación de los activos naturales y paisajísticos. La reproducción de elementos visuales reiterativos en centros históricos, zonas relevantes de la ciudad son objeto de intervención y crítica en la medida que contaminan visualmente el paisaje urbano. Se desvalorizan los escenarios de la ciudad (Mendez y Carmen, 2013), sobre todo la composición del espacio privado menguado por la excedencia de las imágenes en la extensión espacial (Chmielewski et al., 2016). La degradación de la calidad visual de los centros históricos de la ciudad causada por los carteles comerciales que se muestran en las fachadas de los edificios y en los espacios públicos tiene una referencia directa con las dinámicas económicas del espacio.

\section{Publicidad popular}

La publicidad se presenta como un discurso enunciado que persuade, crea comportamientos en consumidores y promueve ventas determinado por un contexto mediático, social y económico (Vakratsas y
Ambler, 1999). Dicho esto, la publicidad popular peruana es motivada por las diferentes instancias sociales, generalmente precarias y laboralmente informales, que hacen posible la emergencia de una gestión visual particular. Esto quiere decir que la publicidad popular se produce desde lo glocal (Dürrschmidt y Kautt, 2018). Desde los principales representantes del diseño popular peruano, como Víctor Escalante o Jesús Ruiz Durand, se ha logrado fusionar tendencias de vanguardia global (Pop y Op Art) con estilos gráficos populares locales (pop achorado) siendo en el consumo masivo donde estas características sinérgicas o glocales se acentúan (Sánchez, 2017). La reproducción de la fuerza de trabajo en escenarios urbanos informales crea inesperadamente una atmosfera cromática explosiva, ruido cromático y figurativo no solo retratado en el diseño gráfico, sino también en el baile y música popular (Bailón y Nicoli, 2009).

Pese a poblar el espacio urbano, no todas las manifestaciones populares de la publicidad (carteles, pancartas y letreros de gráfica popular peruana) destacan en la construcción de un city branding y un nation branding (Cánepa, 2016). El diseño chicha es quizá la excepción. También conocido como 'cartel popular chicha', funcionó en principio como la estética del llamamiento al concierto de música popular emergente en los conos de Lima y en el centro de la ciudad (Bailón y Nicoli, 2009). Según Caroline Hodges et al. 
(2016) la gráfica popular chicha adquiere sentido dentro del marco económico emergente, primero como la forma visual que acompaña una cultura popular desde la década de los años sesenta y, después, visibilizada por una lógica mercantil más estilizada, sintética y armónica en negocios gastronómicos (restaurantes, pequeños bares). En el cartel chicha, los elementos gráficos poseen una composición no regida por los cálculos visuales estilizados, asimismo, los elementos poseen mayor tendencia a la aglutinación visual en tanto congestión de elementos visuales que comulgan con las imágenes heterogéneas del espacio urbano (FigueroaSaavedra, 2007). Esta estética reconocida en la gráfica peruana se encuentra presente en la mayoría del diseño latinoamericano. Andrés Moreno (2014) estudia la gráfica popular en Colombia creando la relación entre el barrio y la producción de una entropía visual carente de estándares estéticos y normativos. A pesar de sus distancias con los patterns visuales canónicos, la gráfica popular llega a convertirse en un patrimonio gráfico vinculado al concepto de identidad cultural, sentido de familiaridad y pertenencia al espacio urbano siempre en pugna con su propia sobreproducción producto del mercantilismo de la ciudad (Fernández y Herrera, 2009). No obstante, aunque los procesos visuales pueden ser reconocidos partiendo de algunos códigos o categorizaciones, se considera precipitada la mención de un "estilo de diseño latinoamericano" (Álvarez, P., 2011). Las diferencias visuales entre las culturas latinoamericanas encuentran similitudes en tanto se encuentran atravesadas por un solo proceso económico de producción, no obstante, los matices que las diferencian pasan por el tratamiento e intervención de las semióticas culturales que imprimen sus singularidades en producción de las imágenes. Según Dagatti y Siganevich (2013) la producción realizada en Argentina en la década del siglo XX (época de fuerte crisis institucional), por ejemplo, desarrolló una semántica y estética de la precarización en la publicidad popular argentina. En este sentido, las crisis, dinámicas y transformaciones económicas y políticas componen el nivel plástico, figurativo y axiológico del diseño.

\section{Metodología}

El propósito de la presente investigación es de carácter cualitativo en tanto su objetivo general es analizar el rol de los componentes plásticos de la publicidad popular en las interacciones comerciales en espacios de saturación y contaminación visual en el centro de Lima, Perú. Su diseño es etnográfico interesado en la examinación, interpretación y descripción de los valores compartidos, aprendidos en grupos culturales concretos 
(Creswell, 2013; Álvarez Gayou, 2003). Como parte de este diseño se han asumido dos objetivos específicos: (i) analizar desde una perspectiva semiótica los componentes plásticos de la imagen presentes en los anuncios publicitarios populares en espacios de saturación visual, (ii) identificar las interacciones comerciales que se asientan en los espacios de contaminación visual en el Centro de Lima, Perú. El desarrollo de ambos objetivos asume a la semiótica como técnica de análisis de datos (Sayago, 2014) que no solo permite la descripción exhaustiva de una muestra representativa de la publicidad popular, sino de la identificación, a través de observación no participante, de valores producidos por la significancia de las vivencias e interacciones en la cultura de producción gráfica en el centro de Lima (Marsciani, 2007).

Como técnica de análisis, el enfoque semiótico se compromete con el modelo de la semiótica plástica (Greimas, 1994; Grupo $\mu$, 1993; Floch, 2000) identificando categorías topológicas (análisis de la organización espacial de los elementos), eidéticas (formas y sus relaciones) y cromáticas (cromemas, consonancia, disonancia, etc.) para vincularlas con el modelo tensivo de Claude Zilberberg (2006, 2016) centrado en los devenires sintácticos de la intensidad (plástica) del anuncio publicitario popular. Los materiales gráficos que se analizarán resultan unidades coherentes enmarcadas dentro de un programa de significación social asumida como caso de estudio. Desde esta perspectiva, se seguirá el proceso del análisis semiótico de la imagen que aísla cada texto o género de texto para su tratamiento particular. La muestra de 500 piezas publicitarias populares fue recogida entre los meses de julio y octubre del 2019 centrando el análisis en 436 piezas gráficas que responden a la saturación del modelo aplicado (Greimas y Courtés, 1982), es decir, en la reiteración en los datos recogidos por el análisis dejando de ofrecer nueva información en una muestra más amplia (Strauss y Corbin, 2002). Asimismo, se procedió a la selección y recolección del material gráfico publicitario en el espacio de producción de estas imágenes, el centro comercial 'Centro Lima' en la avenida Bolivia y la Galería Wilson en la avenida Garcilaso de la Vega en el centro de la ciudad de Lima (Cercado de Lima).

Desde la perspectiva semiótica la representatividad puede ser obtenida por muestras estadísticas o, como sucede en esta investigación, por la saturación del modelo aplicado (Greimas \& Courtés, 1982). Es decir, el corpus - el material gráfico- dejó de ofrecer datos nuevos para el modelo (semiótica plástica: tonicidad, topológico, eidético y cromático) en un número superior a la muestra consignada. Sobre el procedimiento del análisis, este parte del paradigma interpretativo de la semiótica que sigue los siguientes tres principios: (i) adecuación: se selecciona (y textualiza) una muestra finita de 
enunciados visuales (500) y se construye el modelo (semiótica plástica y tensiva) que garantice su adecuación al objeto de estudio. Desde esta motivación se optó por el uso de la relación entre las categorías intensidadfiguratividad al de iconización-figuratividad ya que no tenía pertinencia en el análisis de la publicidad popular; (ii) descripción: se provocó una interpretación (de lo deductivo a lo inductivo) como resultado del proceso descriptivo de las unidades visuales a partir del modelo, y (iii) exhaustividad: se reitera el análisis hacia la totalidad de los elementos observados (corpus) para provocar la saturación del modelo. Los tres procesos son parte del procedimiento de análisis semiótico asumido en la investigación (Greimas y Courtés, 1982; Grupo $\mu$, 1993; Floch, 2000).

La muestra ha dejado de lado el análisis del diseño de tarjetas de presentación y material gráfico producido para eventos privados (reuniones privadas, celebraciones, onomásticos) ya que son parte de la publicidad gráfica subsumida al espacio íntimo, no afectando la circulación pública. Por ello se ha priorizado material publicitario móvil (volantes, trípticos, dípticos) y fijo (banners, afiches) en tanto elementos que transforman al espacio como acción y no solo como espectáculo visual

\begin{tabular}{|l|l|}
\hline Figura 1. & $\begin{array}{l}\text { Figura 2. } \\
\text { Recorte espacial a observar }\end{array}$ \\
\hline Fuente: archivo personal del autor. & Mona ("Wilson")
\end{tabular}

Global Media Journal México 17(33). julio - diciembre 2020. Pp. 96-122. 


\section{Tabla 1.}

Relaciones de actividades laborales en el centro comercial

1. Grupo 1 Trabajadores de talleres de diseño

- Diseñadores

Principalmente hombres

Edad (20-38 años)

- Recepcionistas

Principalmente mujeres

Edad (24-35 años)

\section{Espacio de trabajo}

Local $3 m^{2}$

Diseñadores: Computadora de

diseño dando espaldas al pasillo de

tránsito.

Recepcionistas: Atendiendo dando

cara al pasillo.

Local 4-5 $\mathrm{m}^{2}$

Sótano de la galería

Mayormente hombres

Edad asistentes (25-28 años)

Edad operarios (25-55 años)

\section{Grupo 3. Consumidores en corredores y pasillos}

- Clientes eventuales, caminantes

Pasillos largos, detenidos a comer

Hombres y mujeres

un bocadillo, caminata rápida para

Edad (27 a 56 años) recoger productos, solicitar diseños.

Nota: A diferencia de los talleres ubicados en su mayoría en el primer, segundo y tercer piso del centro comercial, los trabajadores de talleres de imprenta se ubican en el sótano del recinto, teniendo mayor actividad que los talleres de diseño cuyo trabajo eventualmente hace que las recepcionistas consulten en el sótano alguna particularidad del servicio.

Por otra parte, para allanar al segundo objetivo específico, se procede a la recolección de datos a través de la técnica de observación no participante y 15 entrevistas semiestructuradas a 10 clientes y 5 trabajadores del centro comercial. Dichos centros comerciales mantienen cerca de 20 imprentas (sótano) y más de 25 talleres de gráfica publicitaria (segundo y tercer piso) en espacios reducidos y produciendo principalmente para clientes con negocios pequeños y medianos, como personas naturales. Como parte del diseño de investigación etnosemiótico (Marsciani, 2007), las entrevistas a los trabajadores (Grupo 1 y 2) y clientes que circulan rápidamente por la galería (Grupo 3) fueron realizadas por medio de una guía de 12 preguntas cuyas respuestas fueron sometidas al anonimato y confidencialidad de los participantes a través de la codificación 
siguiente: (Grupo, actividad en el espacio, edad). La atención en la forma de relación entre los diferentes usuarios y trabajadores gráficos se documentó en un diario de campo y luego se tradujo en el modelo de interacciones semióticas en espacios comerciales (Floch, 1987) diseñado para reflejar la forma en que los diferentes agentes utilizan el espacio.

\section{Resultados y discusión}

\section{Componentes plásticos de la publicidad popular}

La publicidad popular producida en las galerías de Wilson (Lima, Perú) se encuentra compuesta de formantes visuales desde los cuales se atenderá un análisis plástico propio del plano de la expresión del objeto visual. Es decir, una detenida observación de los elementos visuales del diseño (unidades mínimas del objeto visual) a partir de las categorías topológicas (organización espacialidad en el plano visual), eidéticas (formas, pueden ser geométricas, rectilíneas, orgánicas, etc.) y cromáticas (Greimas, 1994; Grupo $\mu$, 1993; Floch, 2000). Asimismo, asumiremos que cada una de estas categorías visuales que componen el texto plástico del diseño publicitario popular se comprometen con un desarrollo de grados de intensidad sensorial (átona, intermedia y fuerte), fuerza o tonicidad de los elementos (Zilberberg, 2006). Es decir, el interés no solo es la identificación de la forma plástica emergente en el diseño, sino su subordinación a las sustancias sensibles que permiten la excitabilidad sensorial en un sujeto espectador (Grupo $\mu$, 1993), por ejemplo, el tono cromático, los grados de luminosidad o la concentración de unidades gráficas que construyen una visualidad y punto de vista en el diseño (subjetividad). Finalmente, estas características plásticas se aúnan a una lectura figurativa, interesada en el sobrevenir de las figuras o rasgos visuales del objeto visual. Como es presentada por Greimas (1994) la figuratividad posee niveles, grados o variables que le otorgan cierta densidad de rasgos (vestiduras que las hacen más parecidas a la realidad) en el plano visual que puede oscilar desde una abstracción (que le quita la vestidura icónica a las figuras), una densidad mínima (esto es, un numero de rasgos visuales mínimo, necesario y suficiente para permitir su interpretación: el dibujo de niños) hasta una finalmente excesiva (el deseo de hacer-parecer del realismo). No obstante, para nuestro análisis resulta más conveniente presentar a la densidad fuera de la relación figuracióniconización (grados en cómo las figuras se parecen a la realidad de una semiótica natural) para acogerla en el modelo tensivo que presenta a la densidad bajo la relación figuratividad-intensidad, es decir la 
identificación de un número de rasgos figurativos (concentrados o difusos) en relación a la tonicidad (átona o tónica fuerte) en tanto acento de sentido (Zilberberg, 2006). Esta elección metodológica se debe al tratamiento que se hace aquí de la publicidad popular, cuya producción de sentido, postulamos, no se encuentra en la referencia o hacer-parecer real de las figuras (poco importa si el consumidor reconoce en la iconización, una realidad), sino en la carga sensible e intensiva de su nivel plástico engranado a un espacio de consumo. Así, el diseño de la publicidad popular presenta la relación figuratividad-tonicidad en la aglutinación de rasgos visuales, colores cálidos y otros elementos que, como veremos en el análisis, permiten identificar densidades, mínimas, medias o excesivas. Así tenemos el siguiente cuadro que resume estas variaciones visuales:

\section{Tabla 2.}

Sintaxis intensiva de la organización de formantes plásticos

\begin{tabular}{|c|c|c|c|c|}
\hline $\begin{array}{l}\text { Variación de } \\
\text { la tonicidad }\end{array}$ & $\begin{array}{l}\text { Variación de la } \\
\text { densidad } \\
\text { figurativa }\end{array}$ & Presentación plástica & Respuesta del sujeto & $\begin{array}{l}\text { Fórmula } \\
\text { tensiva }\end{array}$ \\
\hline Tonalización & $\begin{array}{l}\text { Densidad } \\
\text { excesiva en el } \\
\text { diseño: } \\
\text { actualización de } \\
\text { aglutinación y } \\
\text { simultaneidad de } \\
\text { elementos en un } \\
\text { mismo plano. }\end{array}$ & $\begin{array}{l}\text { Eidético: sincronía de } \\
\text { formas heterogéneas } \\
\text { (rectilíneas, orgánicas, } \\
\text { irregulares, etc.) } \\
\text { Cromático: colores cálidos, } \\
\text { estridentes. } \\
\text { Topolótico: espacialidad } \\
\text { reducida, sin vacíos. }\end{array}$ & $\begin{array}{l}\text { Afirmación de la } \\
\text { suficiencia: } \\
\text { subjetividades } \\
\text { pasajeras, caminantes } \\
\text { rápidos, sujeto de } \\
\text { acción corporal. }\end{array}$ & $\begin{array}{l}\text { Más } \rightarrow \\
\text { Demasiado }\end{array}$ \\
\hline $\begin{array}{l}\text { Tonicidad } \\
\text { intermedia }\end{array}$ & $\begin{array}{l}\text { Densidad media } \\
\text { del diseño: } \\
\text { actualización de } \\
\text { lo aceptable, } \\
\text { reglamentado y } \\
\text { ordinario. }\end{array}$ & $\begin{array}{l}\text { Eidético: Combinación de al } \\
\text { menos dos tipos de formas. } \\
\text { Cromático: Colores } \\
\text { naturales (azul cielo, verde } \\
\text { naturaleza), medios, con } \\
\text { menor intensidad. } \\
\text { Topológico: } \\
\text { Espacialidad repartida. }\end{array}$ & $\begin{array}{l}\text { Afirmación de } \\
\text { ordinario: } \\
\text { reconocimiento de } \\
\text { elementos culturales, } \\
\text { tipos culturales, } \\
\text { simbólicos. }\end{array}$ & $\begin{array}{l}\text { Más } \rightarrow \\
\text { retiro de al } \\
\text { menos un } \\
\text { más. }\end{array}$ \\
\hline Atonización & $\begin{array}{l}\text { Densidad mínima } \\
\text { del diseño: } \\
\text { Actualización de } \\
\text { la carencia de } \\
\text { rasgos visuales. } \\
\text { Minimalismo } \\
\text { gráfico (diseño } \\
\text { industrial) }\end{array}$ & $\begin{array}{l}\text { Eidético: Al menos una } \\
\text { forma predominante. } \\
\text { Cromático: colores pasteles, } \\
\text { bajos en tonicidad, } \\
\text { acromáticos (blancos, } \\
\text { negros) } \\
\text { Topológico: Espacialidad } \\
\text { dilatada. }\end{array}$ & $\begin{array}{l}\text { Afirmación de la } \\
\text { insuficiencia: } \\
\text { subjetividad comercial } \\
\text { detenida en la } \\
\text { información del } \\
\text { anuncio (sean detalles } \\
\text { críticos, lectura de } \\
\text { costo/beneficio o } \\
\text { mensaje hedonista o de } \\
\text { contenido). }\end{array}$ & $\begin{array}{l}\text { Menos } \rightarrow \\
\text { demasiado } \\
\text { poco. }\end{array}$ \\
\hline
\end{tabular}

Global Media Journal México 17(33). julio - diciembre 2020. Pp. 96-122. 
En el cuadro, la densidad normal, media y excesiva, resultan pertenecer a la sintaxis de una semiótica figurativa atenta a la organización de los formantes visuales, cada una comprometiéndose no solo con un nivel plástico del diseño, sino con un plano intensivo (Zilberberg, 2006) que regula la corporalidad de las personas que circulan el espacio público. Considerando esta sintaxis plástica e intensiva, se presenta un análisis detenido los tres tipos gráficos identificados en el espacio público saturado concluyendo una interacción y sinergia de las tres categorías.

\section{Figura 3.}

Volantes no color

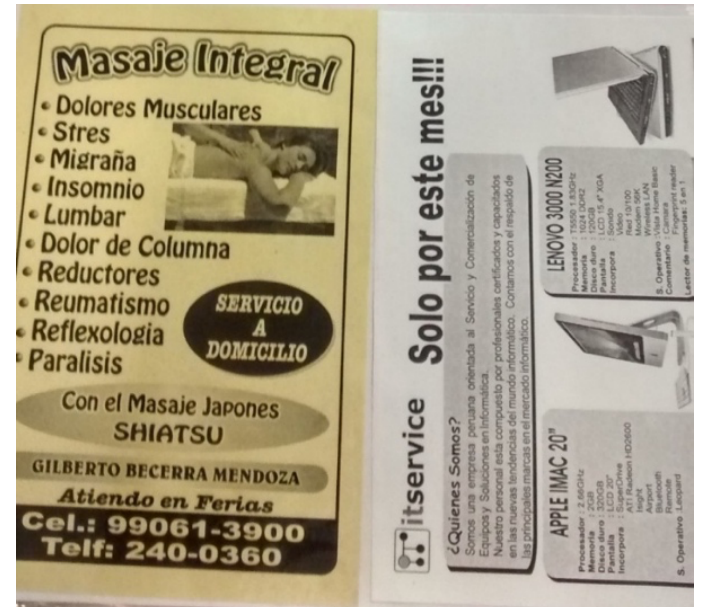

Fuente: registro propio en Galerías Wilson.

En su presentación teórica, un espacio vacío o negativo permite el énfasis y reposo visual en los elementos-figura que se singularizan en el plano (Dondis, 2011). Esta presentación difiere con la gráfica de la publicidad popular cuyos elementos lingüísticos, en vez de permitir la legibilidad o el reposo, funcionan como figuras visuales condensadas que intensifican el objeto visual. En este sentido, la aglutinación de enunciados lingüísticos (en tanto forma visual) intensifica el espacio gráfico creando una lectura total que rehúye de la concentración o el enfoque particular. No se identifica un estímulo publicitario popular en pretensión de un hacer-saber codificado en el mensaje (plano del contenido), más bien se reconoce en la aglutinación y condensación visual un hacer-sentir o contagio sensible que transmite la completitud del servicio, lo abastecido de la oferta de consumo en la pura plasticidad (plano de la expresión). El diseño no propicia significados, sino reacciones asignificantes dirigidas al cuerpo, sensibilidades visuales infranqueables.

En esta misma línea, si bien el diseño global exige características tipográficas que permitan la transmisión de contenidos y significados (Barth, 2008), el uso tipográfico de la publicidad popular es denotativo y lúdico. En otras palabras, el conjunto tipográfico no pretende conducir una significación compleja a ser decodificada, sino construir una funcionalidad (legibilidad) y, a la vez, una euforia de consumo (gratuidad). Compartiendo las tesis funcionales que afirman que el uso de tipografías Georgia o Times New Roman [serif] y Verdana o Arial [sans serif] permiten legibilidad en medios impresos (Mohamad Ali et al., 2013), la publicidad popular utiliza estas mismas formas tipográficas para permitir la legibilidad 
del mensaje. No obstante, incluyen variaciones [typeface] como la familia tipografía Hobo [sans serif] que pretende, a través de sus formas orgánicas y contornos lúdicos, intencionalidades que comportan un uso eufórico, móvil, dinámico e informal en el diseño popular (véase figura 3). Si bien las tipografías más estandarizadas (Arial, Georgia, etc.) son aplicadas con un propósito informativo (legibilidad), la familia tipográfica Hobo (y otras variantes lúdicas), según es utilizado por el grupo 1 de entrevistados, posee un contexto icónico que lo singulariza en el folklore popular, la euforia del día a día y el juego cotidiano, encontrando sus raíces en la década de los sesenta en el cartel popular chicha (Hodges et al., 2016). En este sentido, si bien el molde tipográfico es extranjero, su producción es singularizada (semiotizada) en la cultura de consumo local.

En una categoría distinta se encuentra la densidad media del diseño de la publicidad popular. Si bien comporta muchas de las características antes descritas en la densidad mínima, la densidad figurativa media del diseño popular guarda rasgos singulares: (i) el incremento de la intensidad cromática en el plano visual a través del uso de colores cálidos (rojo, amarillo, naranja) para movilizar al cuerpo-consumidor en acción-reacción y (ii) el uso de figuras icónicas que permiten desligarse ligeramente de un discurso objetual para colocar los efectos utópicos (de consumo global) del producto. En este sentido, se identifica una redundancia (isotopía icónica) de imágenes utópicas (rostros perfectos, occidentales, connotaciones de belleza simbólica memorizadas por el sujeto percibidor) mezcladas en un solo plato gráfico con enunciados críticos o informativos: dirección de ubicación, teléfono para iniciar el contacto, apelación a la historia e insistencia de la "calidad" del servicio (véase figura 4). Si bien el color permite un incremento de la densidad figurativa del diseño, de lo anterior se destaca como formante visual distintivo el uso de rasgos tipo. El tipo es una forma significante que puede ser descrito en una serie de características visuales y cuya significancia se adquiere por identificación y reconocimiento de un contexto icónico y pragmático (Grupo $\mu$, 1993, pp. 137-138), por ejemplo, la presencia de un chullo determina la identificación del ande peruano, el rostro de una mujer blanca y rubia, el ambiente de belleza perfecta. En este sentido, la publicidad popular se compone de figuras tipo como modelos preceptivos formales, abstractos, estables y pseudo universales reconocidos por un sujeto percibidor, encontrados mayormente por los diseñadores populares en las primeras búsquedas en bancos digitales de imágenes (Google), como el rostro femenino de belleza occidental en servicios de cosmética y salones de belleza para provocar un reconocimiento inmediato y eficiente. En otros casos se aprecia el uso de personajes animados populares (desde un sol sonriente hasta Mickey 
Mouse) que funcionan articulando enunciados visuales conocidos por pertenecer a un código de circulación generalizado (lo glocal del diseño). Las figuras tipo son presencias que remarcan una globalidad y pertenencia al consumo más legítimo (formal), en ese sentido, el tipo es la abstracción que homogeniza y admite al bárbaro, informal, segregado en la cultura universal de consumo. Hasta aquí, se resuelve que los elementos de la publicidad popular se presentan aglutinados en un agrupamiento heterogéneo de rasgos figurativos que densifican el material gráfico circulante en el espacio público. En este sentido, identificamos a la densidad mínima y media como dependientes y subordinadas a la densidad excesiva de la publicidad popular (véase figura 5). Al concentrar aún más la aglutinación de elementos y sumar una intensificación del color que soporta esa organización, la densidad excesiva de la publicidad popular despoja toda lectura detenida en las partes para construir una totalidad visual, un solo golpe sensible. Todo el nivel plástico de la gráfica popular está diseñado para un consumo en un tiempo breve y más o menos directo, dicho de otro modo, se piensa el diseño en función de la saturación. A diferencia de las imágenes artísticas que pueden crear líneas de fuga culturales en el espacio social (Figueroa-Saavedra, 2007), el uso de una densidad figurativa excesiva de la publicidad popular se encuentra ensamblada al espacio público economizado, dinámico, cambiante y discontinuo (Dagatti y Siganevich, 2013; Martuccelli, 2015).

\section{Figura 4}

Banner para salón de belleza

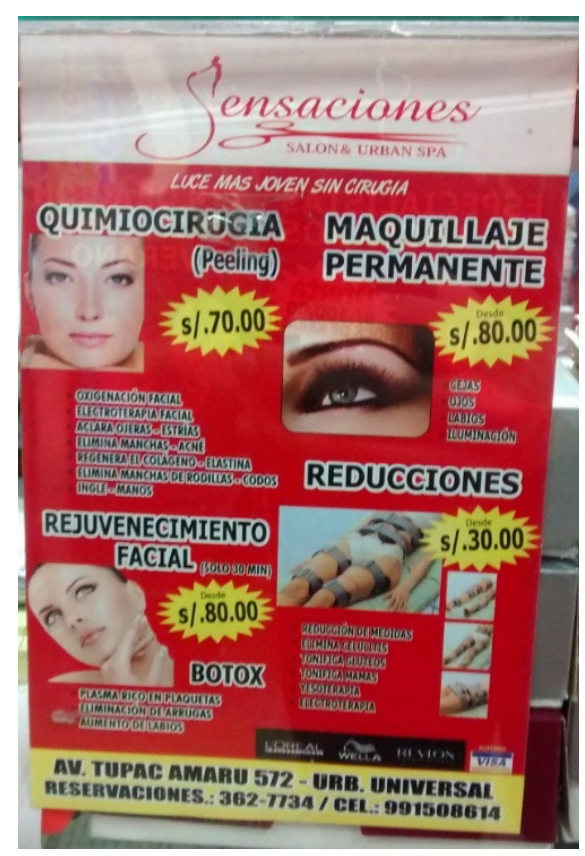

Fuente: archivo personal del autor.

Se observa en la siguiente imagen tomada en una de las intervenciones (véase figura 5) la exposición dichas significancias espacializadas: aglutinación eidética, aguzamiento visual, exceso discursivo y la intempestiva onda cálida de colores de venta directa, colores intensos, cálidos y saturados que optimizan el encuentro sensible estésico-y físico entre el consumidor y el objeto de consumo. En este sentido, la publicidad es objetal, porque todo su nivel plástico crea un punto de vista dirigido al producto, busca el contrato Sujeto-objeto, consumidor-mercancía. 
Figura 5.

Volante diseñado para su circulación en el espacio público

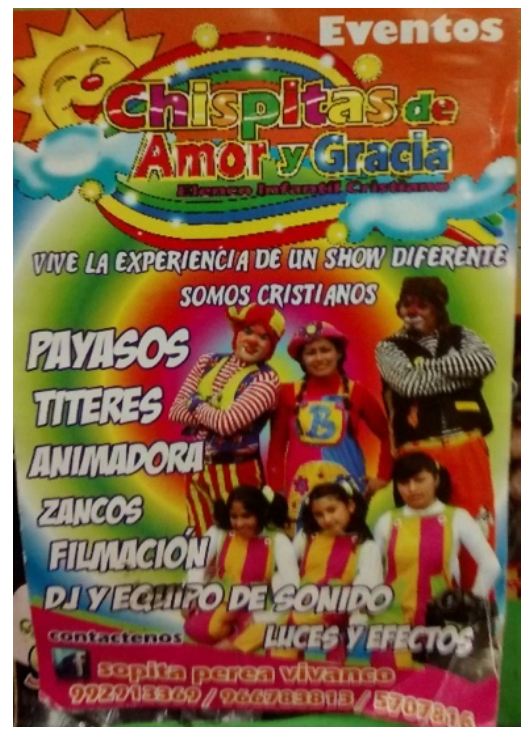

Fuente: archivo personal del autor.

Lo importante del anuncio publicitario (figura 5) no son los detalles de los elementos, sino la mirada que, de golpe, interpela al consumidor hacia un hacer práctico corporal: el hecho semiótico de la publicidad popular no se encuentra dirigido a crear significados $\mathrm{y}$ respuestas mentales en un sujeto, sino a producir una palpitación, una reacción corpórea, una agitación, un espasmo comercial. Dicho esto, consideramos la particularidad de una mezcla de elementos de densidad, una media y otra excesiva en plena convergencia, sin permanecer independientes. El diseño popular es relacional. Es decir, se reconoce una semiótica mixta que fusiona los elementos figurativos de una densidad media (tipos visuales culturales, rasgos visuales de familia como los rostros utópicos) con los de una densidad figurativa excesiva (signos significantes del producto, exceso de información, fondo rojo que enciende e impide al mismo tiempo la lectura detenida).

Tal como funciona en el espacio, el régimen gráfico de la publicidad popular y los múltiples grados de densidad, no representa una realidad social, tampoco se agota en la referencia cultural que lo perpetua en mito. Consideramos aquí a las piezas gráficas como objetos topológicos que se asocian como engranajes del espacio semiótico, público y economizado, en el Centro de Lima. Los objetos topológicos, el diseño gráfico popular, forman parte del espacio como extensiones, interfaces o dispositivos que construyen una significación cultural a través de diferentes isotopías (económicas, laborales, culturales, tecnológicas). La pretensión de considerar al diseño como un objeto engranado del espacio semiótico nos permite analizar la semiótica figurativa y plástica como topológicamente funcionales y no como representantes del espacio o de una realidad. En este sentido, la redundancia (isotopía plástica) de colores cálidos, formantes visuales aglomerados e información sobrecargada buscan producir una acción-reacción en el cuerpo-consumidor. La publicidad popular produce un efecto de sentido utilitario, es decir, la búsqueda no de una lectura detenida de la información, sino la construcción de una lectura total y simultanea de elementos que asaltan en un solo golpe visual y movilizan al cuerpo a actuar. 


\section{Interacciones comerciales en el espacio saturado}

Respecto a la identificación de las interacciones comerciales que se asientan en los espacios visualmente contaminados en el Centro de Lima, se lograron reconocer 4 tipos: (i) visitantes: de trayectos no-discontinuos, que sobre paran para efectuar preguntas críticas (precio, cantidad, detalles del producto) en puestos de venta concretos; (ii) parroquianos: de trayectos continuos, reposan en un sitio especifico (bancas, escalones, sillas de un restaurante) descansando de la dinámica de la calle y apreciando el recuento del día, pueden atender más los detalles del movimiento y los signos gráficos; (iii) callejeros: de trayectos no-continuos, van fugaces de un punto de venta a otro, de un establecimiento a otro bajo la lógica del paseo, $\mathrm{y}$, finalmente, (iv) prácticos: de trayectos discontinuos, orientados al consumo efímero y funcional. Es preciso notar que los cuatro trayectos no son identidades fijas que preceden al espacio contaminado visualmente, sino espacialidades entendidas como trayectos, subjetividades móviles dependientes de los devenires territoriales (Fontanille, 2017; Landowski, 2012). En este sentido, la mayoría de entrevistados afirmaron rechazar la abundancia de imágenes en el centro de Lima, no obstante, la consideran parte de la continuidad espacial, es decir, naturalizan lo caótico del consumo.

Las interacciones entre estos trayectos son constantes, la polaridad/continuidad//discontinuidad/ marca el tránsito de las interacciones y las prácticas que realizan los caminantes en el espacio público, aledaño al Centro comercial. Así, por ejemplo, uno de los entrevistados articula el recorrido de lo /discontinuo/ -> /no-discontinuo/ $\quad->$ /continuo/, es decir, de un trayecto de consumo práctico a uno más sosegado: "Vengo a descansar las piernas con un juguito [...] yo de acá voy a [avenida] Amazonas, de ahí vuelta tengo que venirme para acá" (Grupo 3, parroquiano, 46 años). Otros actualizan recorridos de regreso a la no continuidad y, posteriormente, a lo discontinuo: "[yo voy] de pasada, estaba preguntando por case [celular] [...] después voy para Magdalena para dejar mercadería" (Grupo 3, trayectoria práctica, 34 años). Las prácticas que se destacan de estos trayectos son fragmentadas, informales $\mathrm{y}$ efímeras (Rojas, 2014). A diferencia de otras formas de consumo (Mall, supermercados), la sensibilidad del trayecto es más inmediata, concentrada, fugaz y poco fiel a las relaciones. En algunos casos, por la recurrencia de las formas de vida identificadas, los visitantes son los que logran generar lazos estables por haber encontrado un servicio más eficiente (menos costoso) o un diseño más a su medida: "no son todos, pero si hay gente, amigos que vienen. Ya saben, pues." (Grupo 1, Diseñador taller de

Global Media Journal México 17(33). julio - diciembre 2020. Pp. 96-122. 
diseño, 24 años). No obstante, pese a su singularidad, las rutinas de consumo privilegian más la búsqueda de contacto entre los diseñadores y aquellos trayectos discontinuos y no-continuos en tanto son lo inhóspito del consumo.

Desde la perspectiva de los diseñadores, cuya jornada laboral se desarrolla hasta las 9 a 10 pm —más en el caso de los talleristas - de los cuatro tipos de interacciones identificadas, aquellos trayectos discontinuos y no-continuos, los callejeros y prácticos, son los que subordinan a los demás. Son los callejeros y los prácticos aquellos que desarrollan consumos efusivos, rápidos en pretensión de la funcionalidad, buscan calidad, precio, pero sobre todo rapidez en el consumo. En este sentido, es importante observar la construcción de lo inhóspito (el aún no $\rightarrow$ ya) del consumo que genera escenas prácticas que giran en torno a la espera. Los diseñadores pueden esperar tranquilamente según la hora y el día de la jornada laboral lo in-esperado del consumo (lo no-continuo y lo discontinuo), otras veces jalan a los clientes en una lógica comportamental desesperada. En este sentido, el tiempo de trabajo posee sensibilidades que buscan contagiar a los distintos trayectos reconocidos para lograr la retención y por tanto la conversión económica; la ganancia a través del servicio ofrecido.

\section{El rol de la gráfica popular en las interacciones comerciales}

La funcionalidad de esta forma gráfica con el espacio se encuentra en proporción directa con la rapidez del desplazamiento, caminata economizada de los consumidores, la demanda inmediata del servicio. Una de las entrevistadas menciono que: "vengo al $175 \mathrm{C}$ para recoger unos sellos [...] de ahí me voy al banco para hacer un depósito" (Grupo 3, caminantes consumidores de la galería, 22 años), este apunte es coherente con otro entrevistado, trabajador de un taller de diseño, diseñador: "La gente va y viene, piden que les hagas logos, diseño, volantes, todo pues, y será pues 15 minutos que los atendemos, rápido". (Grupo 1, Diseñador taller de diseño, 31 años). No se busca que el consumidor movilice una lectura, sino la connotación de una gama completa del servicio ofrecido. En este sentido, la identificada densidad excesiva del diseño de la publicidad popular comparte la producción con el cartel chicha inicialmente diseñado para un consumo rápido y efímero (Hodges et al., 2016) que aquí hemos reconocido como consumo de trayectos discontinuos (prácticos) y no-continuos (callejeros). Precisamente, según Caroline Hodges et al. (2016), el uso de colores saturados en el cartel "chicha" se debe a la pretensión de simbolización de /modernidad/, /globalización/ y /aspiracionalidad/, lo cual remarca, desde el punto de vista sostenido 
aquí, una figurativización espacial y horizontal (exteroceptiva) más que abstracta (interoceptiva). Es decir, al igual que el cartel popular "chicha", los colores de la publicidad popular no son utilizados para representar conjuntos significantes abstractos (una dimensión noológica o mítica), sino redundancias figurativas enlazadas, en tanto objetualidad, con el espacio: colores cálidos intensos que atraen trayectos discontinuos y no continuos, aglutinaciones que provocan lecturas de caminatas fugaces y de estancia efímera. Dicho de otro modo, los signos no representan realidades, son más bien engranajes integrados horizontalmente en dichas realidades, son funcionales a los cuerpos de tránsito en el consumo informal. Se construye un espacio fluidificado (BassoFossali, 2009) capaz de sostener las dinámicas de subjetividades con expectativas y trayectos específicos. Justamente, la cooperación espacial de la gráfica de la publicidad popular se registra a través de su plasticidad (colores, formas, topología), idónea para las interacciones fugaces propias de una economía informal (Bailón y Nicoli, 2009; Rojas, 2014)

No es posible negar la existencia de una contaminación visual a través de vallas, banners y volantes publicitarios (Ahmed et al., 2019), además de la identificación de una urbanidad fragmentada (Cercleux et al., 2016), no obstante, se identifica una funcionalidad que no perturba el trayecto de las interacciones comerciales, más bien se trasluce en una disposición cooperativa a estas economías. Por tanto, pese a que la saturación icónica publicitaria se ha estudiado en torno a la lógica de la contaminación, su deformación no resulta ser un excedente despreciable por las formas de vida circundantes del espacio de producción gráfico (Centro comercial, Wilson), sino perfectamente articuladas a este. Al ser considerado engranaje, la caminata de los clientes eventuales de la galería se convierte en una forma significante del espacio fluidificado (Basso-Fossali, 2009) convergente con el diseño popular que busca, a través de una densidad excesiva de la dimensión plástica y figurativa, atraer, retener, anclar la caminata económica (acelerada y fugaz) en el espacio público. Dentro de las entrevistas logradas al Grupo 1 y 2, los entrevistados describen su elección cromática (generalmente cálidos) por motivos físicos y espaciales: “jala más a la vista” (Grupo 1, Diseñador taller de diseño, 27 años). Si entendemos a la saturación como el grado más corto, pero de mayor intensidad posible (Zilberberg, 2006), entonces el diseño publicitario popular es saturado como el propio espacio mercantilizado, contaminado como la propia espacialidad en la que circulan los trayectos de consumo.

Para la literatura general (Nami et al., 2016), la contaminación es entendida como una deformación en el espacio no funcional. Aquí, al contrario, optaremos por la lógica de 
la funcionalidad de las imágenes en el espacio en tanto atendemos a la densidad figurativa excesiva como respuesta de las dinámicas económicas descritas (Suryanto et al., 2020; Rojas, 2014). Por ello, no se considera el punto de vista de la oposición entre el espacio económico precario e informal con una imagen no precaria y congestionada (oposición formal /escaso/ vs /abundante/) sino como la convergencia de un espacio de acción dinámico y móvil con un diseño activo, enérgico $y$, por tanto, eficaz.

\section{Conclusión}

¿Cuál es rol de los componentes plásticos de la publicidad popular en las interacciones comerciales en espacios de saturación y contaminación visual en el centro de Lima, Perú? El espacio público saturado de imágenes publicitarias encuentra en los centros de diseño populares (Wilson) engranajes de producción funcionales al espacio. Es en mercados locales, especialmente latinoamericanos, donde la tensión entre el semiocapitalismo trasnacional y la semiótica comunitaria original encuentran sinergias. El mercado local ha encontrado también sus propias estéticas saturadas en el uso de colores como signos culturales y mentales que no le rinde cuentas al consumo global. Así, los colores populares permiten estéticas separatistas de lo global y más bien se enraízan con la rapidez y velocidad del espacio público mercantilizado: colores saturados, tipografía orgánica y fluida, fondos cálidos y neones que hacen resaltar más el cromatismo urbano y emocional. La tipografía urbana del cartel chicha peruano y del fileteado argentino fueron mucho tiempo gráficas de desborde popular que aparecían ante la ausencia de Estado durante los sesenta, semióticas de resistencia y creatividad popular (Bailón y Nicoli, 2009; Hodges et al., 2016). Hoy, por el contrario, la publicidad popular desmonta funcionalidad y axiología práctica engranada al espacio público despolitizado, eficiente respecto al dinamismo de lo informal y el trabajo precario dinámico. Con ello, las estéticas de resistencia y descodificadas de la década de 1970 son hoy en día elementos que otorgan una familiaridad al consumo, figuras reprogramadas, recodificadas y reajustadas en el mercado. Aquello que se desbordaba y chorreaba como desborde popular está ya reabsorbido por la dinámica del mercado en lo que Verónica Gago (2014) denomina oportunismo de masas. Los colores chillones del gráfico lo miran a uno, no hay una pretensión mental, de interioridad, sino un sentimiento inmediato con lo contiguo cultural. Al nivel del consumo local latinoamericano, el color no sirve para marcar la mente mediante conceptos como /esperanza/ o /felicidad/, sino para relacionarse filiativamente con el entorno de producción. 
El color se hace pragmático y performativo.

Empero, estas fugas de calor local pronto son recodificadas en un precio, un producto, una hora. Con ello, descartamos cualquier tipo de resistencia al mercado en formas de consumo locales de carácter informal denominándolos románticamente multitud fuerzas del contraimperio o fenómenos antisistema.
Queda, para un futuro estudio, pensar en el lugar político de las imágenes en estos espacios mercantilizados, los signos contestatarios (grafitis, publicidad urbana y gráfica sindical) que pueden formularse dentro de una contaminación visual que parece no dejar espacio para estas predicaciones.

\section{Referencias bibliográficas}

Álvarez, P. (2011). Diseño latinoamericano presente y pasado. Breve panorámica. Revista Diseña, 3 , 44-49. https://bit.ly/3gLxmja

Álvarez Gayou Jurgenson, J. L. (2003). Cómo hacer investigación cualitativa: Fundamentos y metodología. Editorial Paidós. https://bit.ly/2KmoiFi

Moreno, A. (2014). Publicidad popular en Bogotá, Una mirada a la gráfica de las tiendas de barrio en la ciudad. Revista e-ikon, 2(1), 89-99. https://app.eam.edu.co/ojs/index.php/eikon/article/view/114

Ahmed, N., Islam, M. N., Tuba, A. S., Mahdy, M. R. C., y Sujauddin, M. (2019). Solving visual pollution with deep learning: A new nexus in environmental management. Journal of environmental management, 248, 109253. https://doi.org/10.1016/j.jenvman.2019.07.024

Bailón, J. y Nicoli, A. (2009). Chicha Power. El marketing se reinventa. Universidad de Lima. Baudrillard, J. (1969). El sistema de los objetos. Siglo XXI.

Bankole, O. E. (2013). Urban environmental graphics: impact, problems and visual pollution of signs and billboards in Nigerian cities. International Journal of Education and Research, 1(6), 1 12. https://www.ijern.com/journal/June-2013/36.pdf

Basso-Fossali, P. (2009) L'espace du jeu. Actes Sémiotiques, 112 https://doi.org/10.25965/as.2541

Barth, S. (2008). Digital designs: A look at the role of real typographic design in effective content delivery. $\quad$ EContent, $31(1), \quad 32-36 . \quad$ https:/pascal$\underline{\text { francis.inist.fr/vibad/index.php?action=getRecordDetailyidt }=20032983}$

Cánepa, G. (2017). Nation Branding. The Re-Foundation of Community, Citizenship and the State in the Context of Neoliberalism in Perú. MedienJournal, 37(3), 7-18. https://doi.org/10.24989/medienjournal.v37i3.116

Chmielewski, S., Lee, D. J., Tompalski, P., Chmielewski, T. J. y Wężyk, P. (2016). Measuring visual pollution by outdoor advertisements in an urban street using intervisibilty analysis and public 
surveys. International. Journal of Geographical Information Science, 30(4), 801-818. https://doi.org/10.1080/13658816.2015.1104316

Cercleux, A. L., Merciu, F. C., y Merciu, G. L. (2016). A model of development strategy encompassing creative industries to reduce visual pollution-case study: Strada Franceză, Bucharest's old city. Procedia Environmental Sciences, 32, 404-411. https://doi.org/10.1016/j.proenv.2016.03.046

Creswell, J. W. (2013). Qualitative inquiry and research design: Choosing among five traditions (3rd ed.). SAGE Publications.

Dagatti, M y Siganevich, P. (2013). El diseño gráfico en la era de la 'precarización de sí'. En L. Elizalde (Comp.), Semióticas gráficas (pp. 92-100). La Crujía.

Dondis, D. A. (2011). La sintaxis de la imagen: introducción al alfabeto visual. Gustavo Gili.

Dürrschmidt, J., y Kautt, Y. (Eds.). (2018). Globalized Eating Cultures: Mediation and Mediatization. Springer. https://doi.org/10.1007/978-3-319-93656-7

Furze, J. (2002). Stealth wind turbines: Designs and technologies to reduce visual pollution. Refocus, 3(2), 18-20. https://doi.org/10.1016/S1471-0846(02)80022-1

Fontanille, J. (2017). Formas de vida (trad. Desiderio Blanco). Universidad de Lima.

Figueroa-Saavedra, F. (2007). Estética popular y espacio urbano: El papel del graffiti, la gráfica y las intervenciones de calle en la configuración de la personalidad de barrio. Disparidades. Revista de Antropología, 62(1), 111-144. https://doi.org/10.3989/rdtp.2007.v62.i1.28

Flad, H. (1997). Country Clutter: Visual Pollution and the Rural Roadscape. The ANNALS of the American Academy of Political and Social Science, 553(1), 117-129. https://doi.org/10.1177/0002716297553001011

Floch, J.-M. (2000). Visual Identities. Continuum.

Floch, J-M. (1987). La génération d'un espace commercial. Une expérience de practique sémiotique. En A.J. Greimas (Comp.) Actes semiotiques (pp. 3-29). Groupe de Recherches Sémiolinguistique.

Fernández, L y Herrera, E. (2009). Hacia la recuperación del patrimonio gráfico popular de nuestros lugares. Convergências - Revista de Investigação e Ensino das Artes, 2(3). http://convergencias.esart.ipcb.pt $/ \mathrm{p}=$ articleyid $=41$

Gago, V. (2014). La razón neoliberal: economías barrocas y pragmática popular. Tinta Limón.

Greimas, A. J. (1980[1976]). Semiótica y ciencias sociales. Fragua

Greimas, A. J. (1994). Figuras y estrategias: en torno a una semiótica visual (trad. Gabriel Hernández Aguilar). Siglo XXI.

Global Media Journal México 17(33). julio - diciembre 2020. Pp. 96-122. 
Greimas, A. J., y Courtés, J. (1982). Semiótica. Diccionario razonado de la teoría del lenguaje. Gredos.

Grupo $\mu$. (1993). Tratado del signo visual. Por una retórica de la imagen (trad. Manuel Talens Carmona). Cátedra.

Harvey, D. (2014) Diecisiete contradicciones del capital y el fin del neoliberalismo. Traficantes de Sueños.

Hodges, C. E., del Carmen, A., y Denegri-Knott, J. (2016). The invisibility of Chicha: A sociohistorical account of the emergence and (re) production of Chicha as 'gráfica popular' in Lima, Peru. En S. Schutt, S. Roberts y L. White (Eds.), Advertising and Public Memory (pp. 158-170). Routledge. https://doi.org/10.4324/9781315677750

INEI (Instituto Nacional de Estadística e Informática). (2018), Producción y empleo informal en el Perú. Cuenta satélite de la economía informal 2007-2007. https://www.inei.gob.pe/media/MenuRecursivo/publicaciones_digitales/Est/Lib1589/libro.p $\underline{\mathrm{df}}$

Kamičaitytė-Virbašienė, J., Godienė, G., y Kavoliūnas, G. (2015). Methodology of visual pollution assessment for natural landscapes. Journal of Sustainable Architecture and Civil Engineering, 13(4), 80-91. https://doi.org/10.5755/j01.sace.13.4.13820

Kim, K., Hayes, J. L., Avant, J. A., y Reid, L. N. (2014). Trends in advertising research: A longitudinal analysis of leading advertising, marketing, and communication journals, 1980 to 2010. Journal of Advertising, 43(3), 296-316. https://doi.org/10.1080/00913367.2013.857620

Kucharikova, Z., y Simko, J. (2017). Visual pollution localization through crowdsourcing and visual similarity clustering. 12th International Workshop on Semantic and Social Media Adaptation and Personalization (SMAP), 26-31. https://doi.org/10.1109/SMAP.2017.8022662

Landowski, E. (2012). ¿Habría que rehacer la semiótica? Contratexto, (020), 127-155. https://doi.org/10.26439/contratexto2012.n020.176

Lee, J. H., y Song, J. H. (2019). Recent trends in advertising and required research in emerging markets-an Asian perspective. International Journal of Advertising, 38, 507-510. https://doi.org/10.1080/02650487.2019.1593741

Martuccelli, D. (2015) Lima y sus arenas. Poderes sociales y jerarquías culturales. Cauces.

Marsciani, F. (2007) Tracciati di etnosemiotica. Franco Angeli.

Mendez, V., y Carmen, A. (2013). Visual pollution in public spaces in Venezuela. Gestión y Ambiente, 16(1), 45-60. https://inis.iaea.org/search/search.aspx?orig_q=RN:45026928

Global Media Journal México 17(33). julio - diciembre 2020. Pp. 96-122. 
Mohamad Ali, A. Z., Wahid, R., Samsudin, K., y Zaffwan Idris, M. (2013) Reading on the computer screen: Does font type has effects on Web text readability? International Education Studies, 6(3), 26-35. https://doi.org/10.5539/ies.v6n3p26

Moraru, M. (2012). Tradition and dogma in romanian advertising. European Journal of Science and Theology, 8(4), 121-129. http://ejst.tuiasi.ro/Files/34/Contents.pdf

Nami, P., Jahanbakhsh, P., y Fathalipour, A. (2016). the role and heterogeneity of visual pollution on the quality of urban landscape using GIS; case study: Historical Garden in City of Maraqeh. Open Journal of Geology, 6(1), 20-29. https://doi.org/10.4236/ojg.2016.61003

Portella, A. (2014). Visual pollution. Advertising, signage and environmental quality. Routledge.

Rojas, M. (2014). Gamarra invisible. El principal emporio del país desde la perspectiva de sus trabajadores. Fondo Editorial de la Universidad Nacional Mayor de San Marcos.

Sánchez, M. (2017). Entre la comunicación y el arte: una mirada a los primeros afiches peruanos. $\begin{array}{lll}\text { Revista } \quad \text { Conexión, } & \text { 6(7), } & \text { 48-59. }\end{array}$ http://revistas.pucp.edu.pe/index.php/conexion/article/view/19011

Sani, S. M., y Shokooh, Y. K. (2016). Minimalism in designing user interface of commercial websites based on gestalt visual perception laws (case study of three top brands in technology scope). Second International Conference on Web Research (ICWR), 115-124. https://doi.org/10.1109/ICWR.2016.7498455

Sayago, S. (2014). El análisis del discurso como técnica de investigación cualitativa y cuantitativa en las ciencias sociales. Cinta de moebio, (49), 1-10. http://dx.doi.org/10.4067/S0717$\underline{554 X 2014000100001}$

Selva, M., y Solà, A. (2004). Modos de representación sujeto y tecnologías de la imagen. En E. Ardèvol y N. Muntañola (Eds.), Representación y cultura audiovisual en la sociedad contemporánea (pp, 175-233). Editorial UOC.

Suryanto, M. E., Adianto, J., y Gabe, R. T. (2020). Accommodating the informal economy in public space. Urbani Izziv, 31(1), 89-100. https://orcid.org/10.5379/urbani-izziv-en-2020-31-01$\underline{003}$

Strauss, A. L., y Corbin, J. M. (2002). Bases de la investigación cualitativa: técnicas y procedimientos para desarrollar la teoría Fundamentada. Sage Publications, Inc. y Editorial Universidad de Antioquia.

Szczepańska, M, Wilkaniec, A, y Škamlová, M. (2019). Visual pollution in natural and landscape protected areas: Case studies from Poland and Slovakia. Quaestiones Geographicae, 38(4), 133-149. https://doi.org/10.2478/quageo-2019-0041

Global Media Journal México 17(33). julio - diciembre 2020. Pp. 96-122. 
Vakratsas, D., y Ambler, T. (1999). How advertising works: What do we really know? Journal of marketing, 63(1), 26-43. https://doi.org/10.2307/1251999

Zilberberg, C. (2016). De las formas de vida a los valores (trad. Desiderio Blanco). Universidad de Lima.

Zilberberg, C. (2015). La estructura tensiva (trad. Desiderio Blanco). Universidad de Lima.

Zilberberg, C. (2006). Semiótica tensiva (trad. Desiderio Blanco). Universidad de Lima.

Zilberberg, C. (2000). Ensayos sobre semiótica tensiva. Universidad de Lima.

Global Media Journal México 17(33). julio - diciembre 2020. Pp. 96-122. 